\title{
Hypoxia-inducible factor 1 alpha in oral squamous cell carcinoma and its
}

\section{relation to prognosis}

Masataka Uehara ${ }^{1}$, Kazuo Sano ${ }^{2}$, Hisazumi Ikeda ${ }^{1}$, Mihoko Nonaka ${ }^{1}$, Izumi Asahina ${ }^{1}$

1. Division of Regenerative Oral Surgery, Unit of Translational Medicine, Graduate

School of Biomedical Sciences, Nagasaki University, 1-7-1 Sakamoto, Nagasaki 852-8588, Japan

2. Division of Dentistry and Oral Surgery, Department of Sensory and Locomotor Medicine, School of Medicine, University of Fukui, Fukui, Matsuoka, Fukui 910-1193, Japan

Corresponding author Dr. Uehara: Division of Reconstructive Oral Surgery, Department of Developmental and Reconstructive Medicine, Nagasaki University Graduate School of Biomedical Sciences, 1-7-1 Sakamoto, Nagasaki 852-8588, Japan

Tel: +81-95-849-7704

Fax: +81-95-849-7705

e-mail: uehara@net.nagasaki-u.ac.jp 


\section{Abstract}

The aim of this study was to investigate the correlation between the expression of hypoxia-inducible factor 1 alpha (HIF-1 alpha) and proliferative activity in tumor cells, lymph node metastasis, as well as prognosis in patients with oral squamous cell carcinoma (OSCC). Fifty-seven biopsy specimens of OSCC were investigated for the expression of HIF-1 alpha and proliferating cell nuclear antigen (PCNA) by immunohistochemistry. None of the patients had received any prior treatments. The percentage of HIF-1 alpha immunopositive area (PHIA) was calculated using computer-assisted image analysis for quantitative assessment of HIF-1 alpha expression. The PCNA labeling index (LI) was evaluated as a proliferation maker. We found that the mean PHIA in all stages was $12.1 \%$ in the poor prognosis patients, and it was $6.4 \%$ in the good prognosis patients. There was a significant difference of PHIA between poor prognosis and good prognosis patients $(\mathrm{P}=0.0065)$. Furthermore, the mean PHIA in the patients who had no metastatic lymph nodes was $7.5 \%$, while it was $11.7 \%$ in the patients who had metastatic lymph nodes. There was also a significant difference of PHIA between patients who had no metastatic lymph nodes and those who had metastatic lymph nodes $(\mathrm{P}=0.0487)$. On the other hand, significant correlation between PHIA and PCNA LI was not observed. These results provide the clinical data 
indicating that HIF-1 alpha may play an important role in lymph node metastasis and prognosis in patients with OSCC.

Key words: hypoxia-inducible factor 1 alpha, oral squamous cell carcinoma, prognosis 


\section{Introduction}

Hypoxia causes cell death if it is severe or prolonged. However, cancer cells acclimatize to this hostile environment. Hypoxia induces many kinds of growth factor and protein, including erythropoietin ${ }^{1}$, vascular endothelial growth factor (VEGF) ${ }^{2}$, endothelin ${ }^{3}$, platelet-derived growth factor (PDGF) ${ }^{4}$, and b-FGF ${ }^{5}$. Their effects are responsible for tumor cell survival in the hypoxic condition, and overexpression of these growth factors and proteins in cancer cells is likely to induce poor prognosis ${ }^{6-10}$. Hypoxia-inducible factor 1 (HIF-1) alpha is a bHLH-PAS transcription factor that plays an essential role in $\mathrm{O}_{2}$ homeostasis ${ }^{11-13}$. The HIF-1 alpha transcription factor mediates transcriptional responses to hypoxia by binding to hypoxia-responsive elements (HRE) present within target genes, such as those encoding growth factors and proteins induced by hypoxia ${ }^{14,15}$. Accordingly, it is speculated that HIF-1 alpha expression plays an important role in the prognosis of cancer patients. Indeed, there were many reports concerning the correlation between expression of HIF-1 alpha in cancer cells and patient mortality $^{16-21}$. However, few studies have reported the correlation between the expression of HIF-1 alpha and prognosis in patient with oral squamous cell carcinoma $(\mathrm{OSSC})^{22}$

On the other hand, there have been some reports investigating the correlation 
between proliferative activity of tumor cells and prognosis in patients with OSCC ${ }^{23-25}$. However, the correlation between HIF-1 alpha expression and tumor proliferative activity in OSCC is still not clearly understood. Because proliferating cell nuclear antigen (PCNA) synthesis occurs in the latter part of the G1 phase and throughout the S phase, while this protein is virtually undetectable in M-phase cells ${ }^{26}$, PCNA is a reliable marker to assess the proliferative activity of cells. The aim of the present study was to elucidate the correlation between the expression of HIF-1 alpha and prognosis as well as tumor cell proliferative activity in patients with OSCC using HIF-1 alpha and PCNA immunohistochemistry. 


\section{Materials and Methods}

\section{Patients and tumor samples}

Biopsy specimens of OSCC were obtained with informed consent from 57 patients at the Nagasaki University Hospital of Medicine and Dentistry. All patients were staged according to the tumor-node-metastasis (TNM) classification of tumors (International Union Against Cancer (UICC)). Ten patients had stage I, 15 patients had stage II, 8 patients had stage III, and 24 patients had stage IV. All patients were fresh cases and had not received any previous treatment. The follow-up period of the disease was from 4 to 16 years after treatment. In our study, good prognosis was defined as patients who were alive without any sign of a tumor, and poor prognosis was defined as patients who died during the observation period as a result of their tumors.

\section{HIF-1 alpha and PCNA immunohistochemistry}

All the specimens obtained from biopsy were fixed in 3.7\% neutral formalin for $24 \mathrm{~h}$.

Processing for routine paraffin embedding followed, and 4.0- $\mu$ m sections were prepared, mounted on poly L-lysine-coated glass slides, and dried overnight on a hotplate at $37^{\circ} \mathrm{C}$ to promote adhesion. Immunohistochemical staining was performed using the avidin-biotin complex method as described herein. 
In the first and second sections, HIF-1 alpha and PCNA immunohistochemical

staining were performed, respectively. Anti-HIF-1 alpha monoclonal mouse antibody (1:500 diluted, mouse antihypoxia-inducible factor 1 alpha monoclonal IgG 2b, Chemicon International, Inc., Temecular, CA, USA) and mouse anti-PCNA monoclonal antibody (PC10, 1:100 diluted, DAKO M0879, Denmark) were applied, followed by diluted biotinylated secondary antibody for 30 min and then $A B C$ reagent for 30 min using the Vectastain Elite ABC Kit (Vector Laboratories, Burlingame, CA, USA). Negative controls, prepared by substituting phosphate-buffered saline (PBS) for the primary antibody, showed no detectable staining.

\section{Quantification of HIF-1 alpha and labeling indices of PCNA}

The HIF-1 alpha expression was assessed in terms of percentage of HIF-1 alpha immunopositive area (PHIA) in the tumor through computer-assisted image analysis (Macintosh Image 1.62 on a PowerBook G4, Apple Computer, Cupertino, CA, USA). Immunohistological sections were photographed using a Nikon digital camera, Coolpix 4500 (Nikon Co., Tokyo, Japan), at a 50 x magnification. After saving the captured image in a personal computer, the image was cropped to a 256 x 256 pixel image. After noise reduction treatment and edge enhancement, image analysis was performed 
according to the method of Wu et $\mathrm{al}^{27}$.

The PCNA labeling index (LI) of tumor cells was defined as the percentage of PCNA-positive cells in 1000 tumor cells counted from four randomly selected fields. Labeled and unlabeled cells were counted with the aid of a squared eyepiece graticule (Nikon, Tokyo, Japan) at a magnification of x400.

\section{Statistical analysis}

The statistical analysis for prognosis and PHIA and/or PCNA LI was performed using the Mann-Whitney U-test. Furthermore, Pearson's correlation coefficients were determined for PHIAs and PCNA LIs. Data were considered statistically significant if $P$ values were less than or equal to 0.05 . 


\section{Results}

HIF-1 alpha expression and percentage of HIF-1 alpha immunopositive area

HIF-1 alpha expression was found in all specimens. The expression was mainly confirmed by the presence of brown-stained nuclei and/or cytoplasm of tumor cells (Fig.

1). Accordingly, the PHIA was calculated to precisely assess the quantification of HIF-1 alpha. The extent, intensity, and distribution of staining seen were heterogeneous, and it was found regularly around areas of necrosis.

Seventeen of the 57 patients had metastatic lymph nodes. The average PHIA was $7.5 \%$ in the patients who had no metastatic lymph nodes, while it was $11.7 \%$ in the patients who had metastatic lymph nodes. The PHIA of patients who had metastatic lymph nodes was significantly higher than that of patients who had no metastatic lymph nodes (Fig. 2a; $\mathrm{P}=0.0487$ ). Twenty-four of the 57 patients had a poor prognosis in all stages. In the poor prognosis patients, the average PHIA was $12.1 \%$, while it was $6.4 \%$ in the good prognosis patients. There was a significant difference in the PHIA values between patients with poor prognosis and those with good prognosis (Fig. 2b; $\mathrm{P}=0.0065$ ). In the stage I and II patients, 9 of the 25 patients had a poor prognosis. The reasons for poor prognosis in these patients included 1 case of local recurrence, 4 cases of delayed lymphatic metastasis, and 4 cases of pulmonary metastasis. The 
average of PHIA was $8.2 \%$ in the good prognosis patients and $11.6 \%$ in the poor prognosis patients. There was no significant difference in the PHIA values between poor prognosis patients and good prognosis patients (Fig. 3a; $\mathrm{P}=0.9323$ ). In the stage III and IV patients, 15 of 32 patients had poor prognosis. The reasons for poor prognosis in these patients included 11 cases of local recurrence, 2 cases of delayed lymphatic metastasis, and 2 cases of pulmonary metastasis. The average of PHIA was 4.6\% in the good prognosis patients and $12.3 \%$ in the poor prognosis patients. There was a significant difference in PHIA values between the poor prognosis patients and the good prognosis patients (Fig. 3b; $\mathrm{P}=0.0065$ ).

PCNA immunohistochemistry and labeling indices

PCNA-positive cells were distinguished by the brown-stained nuclei in immunohistochemical staining. The average of PCNA LIs was $24.9 \%$ in good prognosis patients and $29.0 \%$ in poor prognosis patients. Although PCNA LIs of poor prognosis patients tended to be higher than those of good prognosis patients, there was no significant difference in PCNA LIs between good and poor prognosis patients $(\mathrm{P}=0.4769)$. Additionally, the correlation between PHIA and PCNA LI is shown in Fig. 4. Statistical significance was not observed $(r=0.033, n=57, Y=29.445-0.321 X$, 
$\mathrm{P}=0.1775)$. 


\section{Discussion}

Although it is possible to obtain quantitative antigen information objectively by biochemical assays and flow cytometry, a major disadvantage of these methods is the loss of an observable relationship between the antigen and the tissue morphology, as well as the difficulty of retrospective analysis. Immunohistochemistry is being widely used for histologic analysis in research, and this type of analysis conserves the spatial relationship between the antigen and the tissue morphology. The combination of immunohistochemistry and computer-assisted image analysis systems provides the possibility of objective quantification of the stained structures in relation to the total tissue architecture ${ }^{27-31}$. Because HIF-1 alpha antigen expression was heterogeneous in the OSCC sections, a combination of immunohistochemistry and computer-assisted image analysis was required for both of the observation of HIF-1 alpha antigen distribution and the objective assessment of its quantification in the present study.

Our analysis results demonstrated that PHIA in patients who had metastatic lymph nodes was significantly higher than that in patients who had no metastatic lymph nodes. Tumor metastasis is closely associated with the invasive tumor front, and an infiltrative pattern of invasion shows a greater tendency to metastasize ${ }^{32,}{ }^{33}$. Additionally, the loss of cellular cohesiveness, which results in an infiltrative pattern of 
invasion, has been attributed to dysfunction of E-cadherin ${ }^{34-36}$. On the other hand, Imai et al. ${ }^{37}$ experimentally showed that E-cadherin expression was remarkably decreased under hypoxia in tumor cells. Therefore, we speculated that hypoxic OSCC cells were responsible for the dysfunction of E-cadherin, inducing lymph node metastasis.

We demonstrated in the present study that HIF1-alpha was expressed at a significantly higher level in poor prognosis patients, especially those in stage III and IV. Similar results had been reported in studies where HIF-1 alpha expression correlated with poor prognosis and an aggressive index of cancer ${ }^{16,22}$. Fillies et al. ${ }^{38}$ reported that increased HIF-1 alpha expression was associated with good prognosis in early stage squamous cell carcinoma of the oral floor, but they speculated that expression of HIF-1 alpha is not hypoxia related but is due to alterations in oncogene or tumor suppressor genes. Therefore, we investigated the prognosis of patients with OSCC in stage I, II and stage III, IV, respectively, to investigate the different behavior of HIF-1 alpha expression between early stage OSCC and advanced stage OSCC in the present study. As a result, we demonstrated that HIF-1 alpha expression in stage I, II OSCC was not a prognostic maker. Because poor prognosis in 11 of 15 patients who had stage III or IV cancer resulted from local recurrence, residual tumor cells, which are also closely 
associated with invasive tumor front ${ }^{32}$, were a critical factor for prognosis. The process of tumor cell invasion involves degradation of the extracellular matrix, and matrix metalloproteinases (MMPs) play an important role in invasion in OSCC ${ }^{39-41}$. On the other hand, the authors of one study also pointed out that a hypoxic microenvironment in human OSCC plays important roles in the expression of matrix $\mathrm{MMPs}^{42}$. These findings are indicative that hypoxia in OSCC might be responsible for the enhancement of tumor cell invasion as well as metastasis, resulting in poor prognosis.

We observed a weak inverse correlation between PHIA and PCNA LIs, although there was no statistically significant correlation in the present study. This is consistent with the results from other studies that have used combined assays of proliferation and hypoxia ${ }^{43-46}$. The authors of all of the related studies concur that there is no correlation between overall labeling index of the proliferation markers and measurements of hypoxia. These findings might imply that the overall proliferative activity was independent of overall oxygenation status in OSCC.

In conclusion, expression of HIF1-alpha in OSCC is likely to be of great value to predict the prognosis of OSCC, and could provide important information for a treatment program. 


\section{References}

1. Winter SC, Shah KA, Campo L, Turley H, Leek R, Corbridge RJ, et al. Relation of erythropoietin and erythropoietin receptor expression to hypoxia and anemia in head and neck squamous cell carcinoma. Clin Cancer Res 2005;11(21): 7614-7620.

2. Shweiki D, Itin A, Soffer D, Keshet E. Vascular endothelial growth factor induced by hypoxia may mediate hypoxia-initiated angiogenesis. Nature 1992;359(6398): 843-845.

3. Grimshaw MJ, Naylor S, Balkwill FR. Endothelin-2 is a hypoxia-induced autocrine survival factor for breast tumor cells. Mol Cancer Ther 2002;1(14): 1273-1281.

4. Chen EY, Mazure NM, Cooper JA, Giaccia AJ. Hypoxia activates a platelet-derived growth factor receptor/phosphatidylinositol 3-kinase/Akt pathway that results in glycogen synthase kinase-3 inactivation. Cancer Res 2001;61(6): 2429-2433.

5. Ishibashi H, Shiratuchi T, Nakagawa K, Onimaru M, Sugiura T, Sueishi K, et al. Hypoxia-induced angiogenesis of cultured human salivary gland carcinoma cells enhances vascular endothelial growth factor production and basic fibroblast growth factor release. Oral Oncol 2001;37(1): 77-83.

6. Saintigny P, Besse B, Callard P, Vergnaud AC, Czernichow S, Colombat M, et al. Erythropoietin and erythropoietin receptor coexpression is associated with poor survival in stage I non-small cell lung cancer. Clin Cancer Res 2007;13(16): 4825-4831.

7. Uehara M, Sano K, Ikeda H, Sekine J, Irie A, Yokota T, et al. Expression of vascular endothelial growth factor and prognosis of oral squamous cell carcinoma. Oral Oncol 2004;40(3): 321-325.

8. Ishibashi Y, Hanyu N, Nakada K, Suzuki Y, Yamamoto T, Takahashi T, et al. Endothelin protein expression as a significant prognostic factor in oesophageal squamous cell carcinoma. Eur J Cancer 2003;39(10): 1409-1415.

9. Matsumoto S, Yamada Y, Narikiyo M, Ueno M, Tamaki H, Miki K, et al. Prognostic significance of platelet-derived growth factor-BB expression in human esophageal squamous cell carcinomas. Anticancer Res 2007;27(4B): 2409-2414.

10. Barclay C, Li AW, Geldenhuys L, Baguma-Nibasheka M, Porter GA, Veugelers $\mathrm{PJ}$, et al. Basic fibroblast growth factor (FGF-2) overexpression is a risk factor 
for esophageal cancer recurrence and reduced survival, which is ameliorated by coexpression of the FGF-2 antisense gene. Clin Cancer Res 2005;11(21): 7683-7691.

11. Wang GL, Jiang BH, Rue EA, Semenza GL. Hypoxia-inducible factor 1 is a basic-helix-loop-helix-PAS heterodimer regulated by cellular $\mathrm{O} 2$ tension. Proc Natl Acad Sci U S A 1995;92(12): 5510-5514.

12. Iyer NV, Kotch LE, Agani F, Leung SW, Laughner E, Wenger RH, et al. Cellular and developmental control of $\mathrm{O} 2$ homeostasis by hypoxia-inducible factor 1 alpha. Genes Dev 1998;12(2): 149-162.

13. Ryan HE, Lo J, Johnson RS. HIF-1 alpha is required for solid tumor formation and embryonic vascularization. Embo J 1998;17(11): 3005-3015.

14. Wenger RH, Gassmann M. Oxygen(es) and the hypoxia-inducible factor-1. Biol Chem 1997;378(7): 609-616.

15. Minchenko A, Caro J. Regulation of endothelin-1 gene expression in human microvascular endothelial cells by hypoxia and cobalt: role of hypoxia responsive element. Mol Cell Biochem 2000;208(1-2): 53-62.

16. Aebersold DM, Burri P, Beer KT, Laissue J, Djonov V, Greiner RH, et al. Expression of hypoxia-inducible factor-1alpha: a novel predictive and prognostic parameter in the radiotherapy of oropharyngeal cancer. Cancer Res 2001;61(7): 2911-2916.

17. Bachtiary B, Schindl M, Potter R, Dreier B, Knocke TH, Hainfellner JA, et al. Overexpression of hypoxia-inducible factor 1alpha indicates diminished response to radiotherapy and unfavorable prognosis in patients receiving radical radiotherapy for cervical cancer. Clin Cancer Res 2003;9(6): 2234-2240.

18. Birner P, Schindl M, Obermair A, Plank C, Breitenecker G, Oberhuber G. Overexpression of hypoxia-inducible factor 1alpha is a marker for an unfavorable prognosis in early-stage invasive cervical cancer. Cancer Res 2000;60(17): 4693-4696.

19. Bos R, Zhong H, Hanrahan CF, Mommers EC, Semenza GL, Pinedo HM, et al. Levels of hypoxia-inducible factor-1 alpha during breast carcinogenesis. J Natl Cancer Inst 2001;93(4): 309-314.

20. Schindl M, Schoppmann SF, Samonigg H, Hausmaninger H, Kwasny W, Gnant $\mathrm{M}$, et al. Overexpression of hypoxia-inducible factor 1alpha is associated with an unfavorable prognosis in lymph node-positive breast cancer. Clin Cancer Res 2002;8(6): 1831-1837.

21. Theodoropoulos VE, Lazaris A, Sofras F, Gerzelis I, Tsoukala V, Ghikonti I, et 
al. Hypoxia-inducible factor 1 alpha expression correlates with angiogenesis and unfavorable prognosis in bladder cancer. Eur Urol 2004;46(2): 200-208.

22. Liu SY, Chang LC, Pan LF, Hung YJ, Lee CH, Shieh YS. Clinicopathologic significance of tumor cell-lined vessel and microenvironment in oral squamous cell carcinoma. Oral Oncol 2007;3030.

23. Sano K, Takahashi H, Fujita S, Inokuchi T, Pe MB, Okabe H, et al. Prognostic implication of silver-binding nucleolar organizer regions (AgNORs) in oral squamous cell carcinoma. J Oral Pathol Med 1991;20(2): 53-56.

24. Yue L, Iwai M, Furuta I. Evaluation of argyrophilic nucleolar organizer regions in tongue squamous cell carcinomas. Oral Oncol 1999;35(1): 70-76.

25. Schildt EB, Nylander K, Eriksson M, Hardell L, Magnusson A, Roos G. Expression of p53, PCNA, Ki-67 and bcl-2 in relation to risk factors in oral cancer - a molecular epidemiological study. Int J Oncol 2003;22(4): 861-868.

26. Celis JE, Celis A. Cell cycle-dependent variations in the distribution of the nuclear protein cyclin proliferating cell nuclear antigen in cultured cells: subdivision of S phase. Proc Natl Acad Sci U S A 1985;82(10): 3262-3266.

27. Wu LC, D'Amelio F, Fox RA, Polyakov I, Daunton NG. Light microscopic image analysis system to quantify immunoreactive terminal area apposed to nerve cells. J Neurosci Methods 1997;74(1): 89-96.

28. Ruifrok AC. Quantification of immunohistochemical staining by color translation and automated thresholding. Anal Quant Cytol Histol 1997;19(2): 107-113.

29. Tajima Y, Kawasaki M, Ohno J, Kusama K, Maruyama S, Kato K. Comparative image analysis of EGF immunoreaction in rat submandibular gland using 3,3'-diaminobenzidine with metal enhancer substrate. Biotech Histochem 2000;75(1): 15-18.

30. Leal S, Diniz C, Sa C, Goncalves J, Soares AS, Rocha-Pereira C, et al. Semiautomated computer-assisted image analysis to quantify 3,3'-diaminobenzidine tetrahydrochloride-immunostained small tissues. Anal Biochem 2006;357(1): 137-143.

31. Matos LL, Stabenow E, Tavares MR, Ferraz AR, Capelozzi VL, Pinhal MA. Immunohistochemistry quantification by a digital computer-assisted method compared to semiquantitative analysis. Clinics 2006;61(5): 417-424.

32. Odell EW, Jani P, Sherriff M, Ahluwalia SM, Hibbert J, Levison DA, et al. The prognostic value of individual histologic grading parameters in small lingual squamous cell carcinomas. The importance of the pattern of invasion. Cancer 
1994;74(3): 789-794.

33. Sawair FA, Irwin CR, Gordon DJ, Leonard AG, Stephenson M, Napier SS. Invasive front grading: reliability and usefulness in the management of oral squamous cell carcinoma. J Oral Pathol Med 2003;32(1): 1-9.

34. Frixen UH, Behrens J, Sachs M, Eberle G, Voss B, Warda A, et al. E-cadherin-mediated cell-cell adhesion prevents invasiveness of human carcinoma cells. J Cell Biol 1991;113(1): 173-185.

35. Menezes MB, Lehn CN, Goncalves AJ. Epidemiological and histopathological data and E-cadherin-like prognostic factors in early carcinomas of the tongue and floor of mouth. Oral Oncol 2007;43(7): 656-661.

36. Ghosh S, Munshi HG, Sen R, Linz-McGillem LA, Goldman RD, Lorch J, et al. Loss of adhesion-regulated proteinase production is correlated with invasive activity in oral squamous cell carcinoma. Cancer 2002;95(12): 2524-2533.

37. Imai T, Horiuchi A, Wang C, Oka K, Ohira S, Nikaido T, et al. Hypoxia attenuates the expression of E-cadherin via up-regulation of SNAIL in ovarian carcinoma cells. Am J Pathol 2003;163(4): 1437-1447.

38. Fillies T, Werkmeister R, van Diest PJ, Brandt B, Joos U, Buerger H. HIF1-alpha overexpression indicates a good prognosis in early stage squamous cell carcinomas of the oral floor. BMC Cancer 2005;584.

39. de Vicente JC, Lequerica-Fernandez P, Santamaria J, Fresno MF. Expression of MMP-7 and MT1-MMP in oral squamous cell carcinoma as predictive indicator for tumor invasion and prognosis. J Oral Pathol Med 2007;36(7): 415-424.

40. Patel BP, Shah SV, Shukla SN, Shah PM, Patel PS. Clinical significance of MMP-2 and MMP-9 in patients with oral cancer. Head Neck 2007;29(6): 564-572.

41. Baker EA, Leaper DJ, Hayter JP, Dickenson AJ. The matrix metalloproteinase system in oral squamous cell carcinoma. Br J Oral Maxillofac Surg 2006;44(6): 482-486.

42. Miyazaki Y, Hara A, Kato K, Oyama T, Yamada Y, Mori H, et al. The effect of hypoxic microenvironment on matrix metalloproteinase expression in xenografts of human oral squamous cell carcinoma. Int J Oncol 2008;32(1): 145-151.

43. Wijffels KI, Marres HA, Peters JP, Rijken PF, van der Kogel AJ, Kaanders JH. Tumour cell proliferation under hypoxic conditions in human head and neck squamous cell carcinomas. Oral Oncol 2007;33.

44. Tsang RW, Fyles AW, Milosevic M, Syed A, Pintilie M, Levin W, et al. 
Interrelationship of proliferation and hypoxia in carcinoma of the cervix. Int $J$ Radiat Oncol Biol Phys 2000;46(1): 95-99.

45. Ljungkvist AS, Bussink J, Rijken PF, Kaanders JH, van der Kogel AJ, Denekamp J. Vascular architecture, hypoxia, and proliferation in first-generation xenografts of human head-and-neck squamous cell carcinomas. Int J Radiat Oncol Biol Phys 2002;54(1): 215-228.

46. Hoogsteen IJ, Marres HA, Wijffels KI, Rijken PF, Peters JP, van den Hoogen FJ, et al. Colocalization of carbonic anhydrase 9 expression and cell proliferation in human head and neck squamous cell carcinoma. Clin Cancer Res 2005;11(1): 97-106. 


\section{Legends to figures}

Fig. 1: Hypoxia-inducible factor 1 alpha immunohistochemical findings. Labeled cells have dark-brown-stained nuclei and/or cytoplasm (original magnification x100, Bar=30 m).

Fig. 2a: Percentage of hypoxia-inducible factor 1 alpha immunopositive area (PHIA) in the patients who had no lymph node metastasis (7.5\%) and that in the patients who had lymph node metastasis (11.7\%). Each plot represents the mean; bars show the standard deviation (SD). There was statistical significance in the difference between patients with and those without lymph node metastasis $(\mathrm{P}=0.0487)$.

Fig. 2b: Percentage of hypoxia-inducible factor 1 alpha immunopositive area (PHIA) in poor prognosis patients and good prognosis patients in all stages. Each plot represents the mean; bars show the standard deviation (SD). A significant difference was observed between good and poor prognosis patients $(\mathrm{P}=0.0342)$.

Fig. 3a: Percentage of hypoxia-inducible factor 1 alpha immunopositive area (PHIA) in poor prognosis patients and good prognosis patients in stage I and II patients. Each plot represents the mean; bars show the standard deviation (SD). No significant difference was observed between good and poor prognosis patients $(\mathrm{P}=0.9323)$.

Fig. 3b: Percentage of hypoxia-inducible factor 1 alpha immunopositive area (PHIA) in 
poor prognosis patients and good prognosis patients in stage III and IV patients. Each plot represents the mean; bars show the standard deviation (SD). A significant difference was observed between good and poor prognosis patients $(\mathrm{P}=0.0065)$.

Fig. 4: Correlation between percentage of hypoxia-inducible factor 1 alpha immunopositive area (PHIA) and proliferating cell nuclear antigen labeling index (PCNA LI). $\quad(r=0.033, n=57, Y=29.445-0.321 X, P=0.1775)$. 


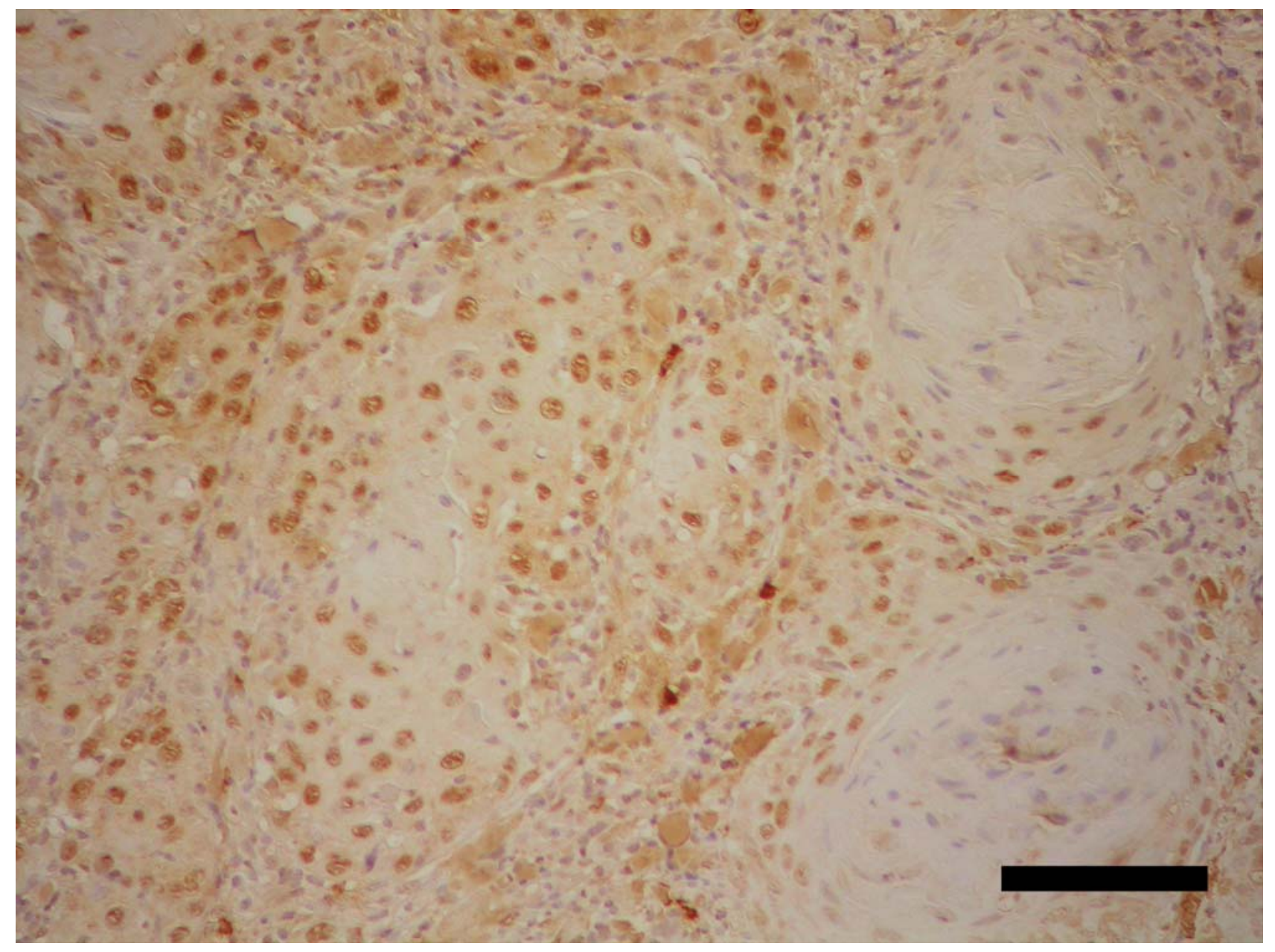

Figure 1 
Lymph node metastasis

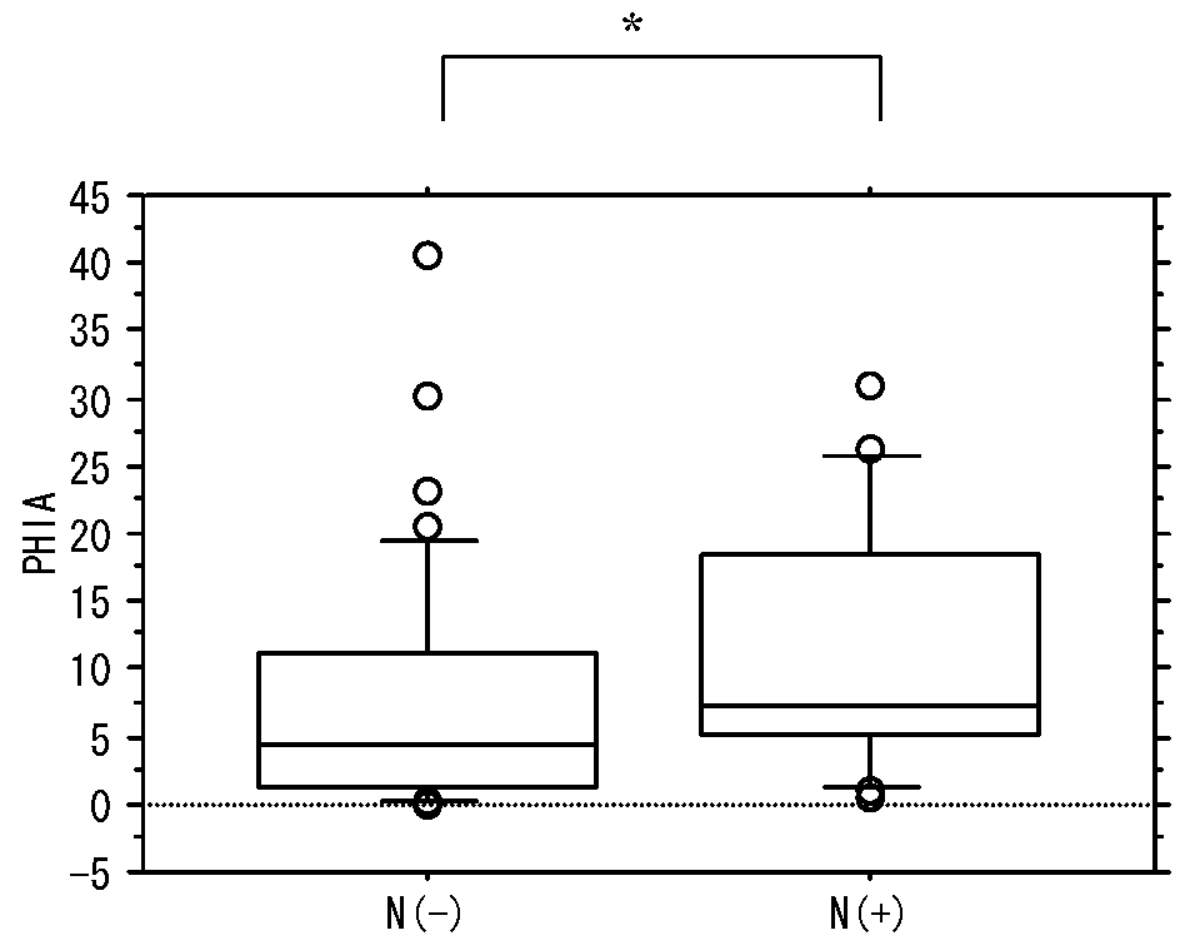

Figure 2a 


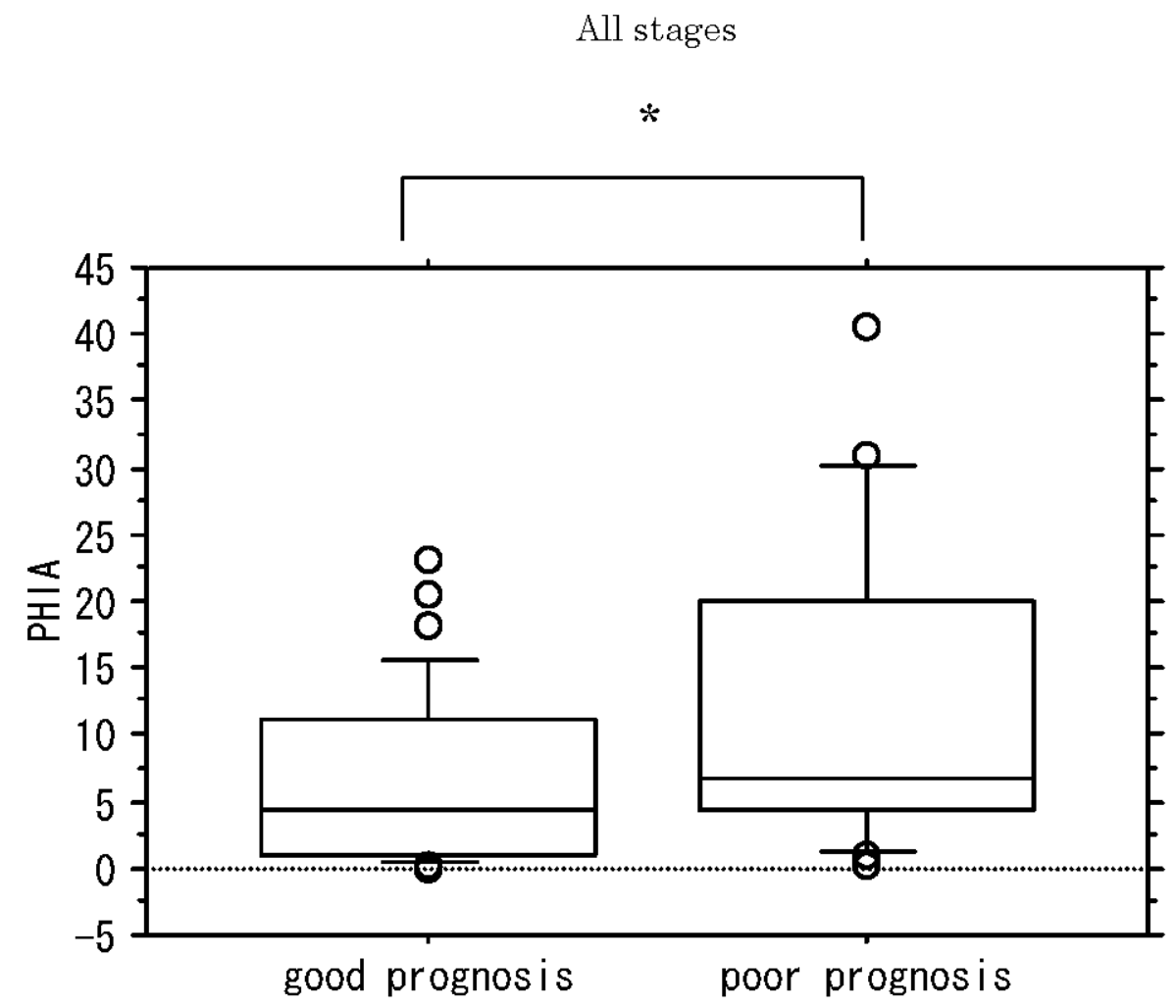

Figure $2 b$ 
Stage I, II

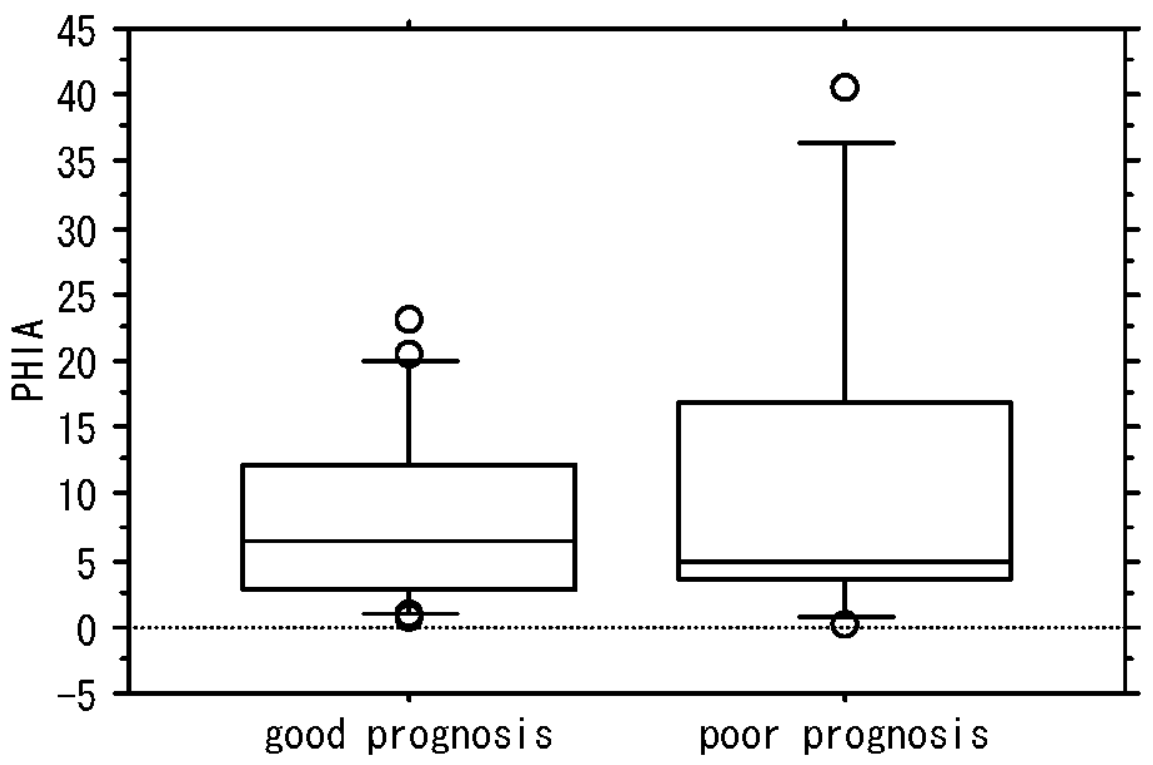

Figure 3a 
Stage III, IV

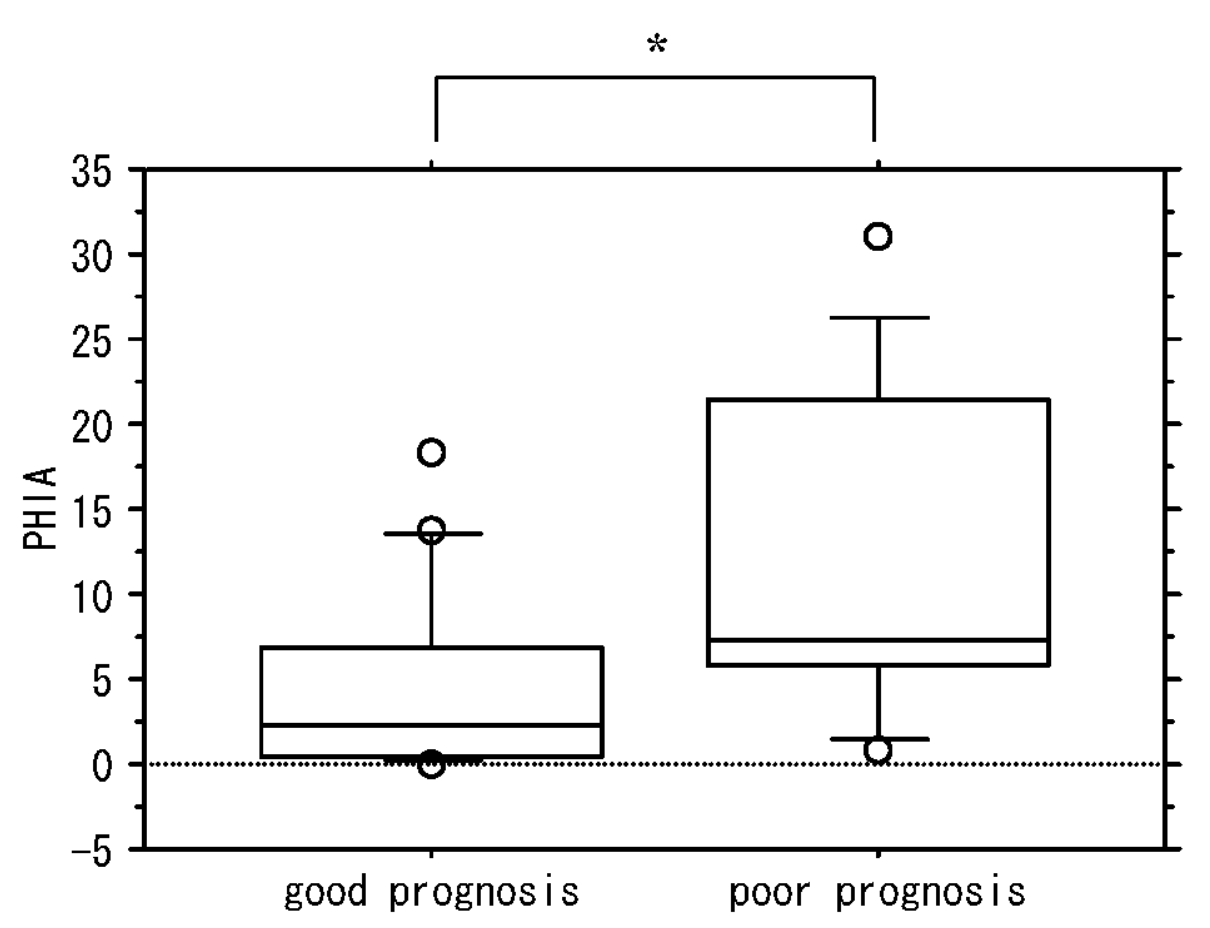

Figure $3 b$ 


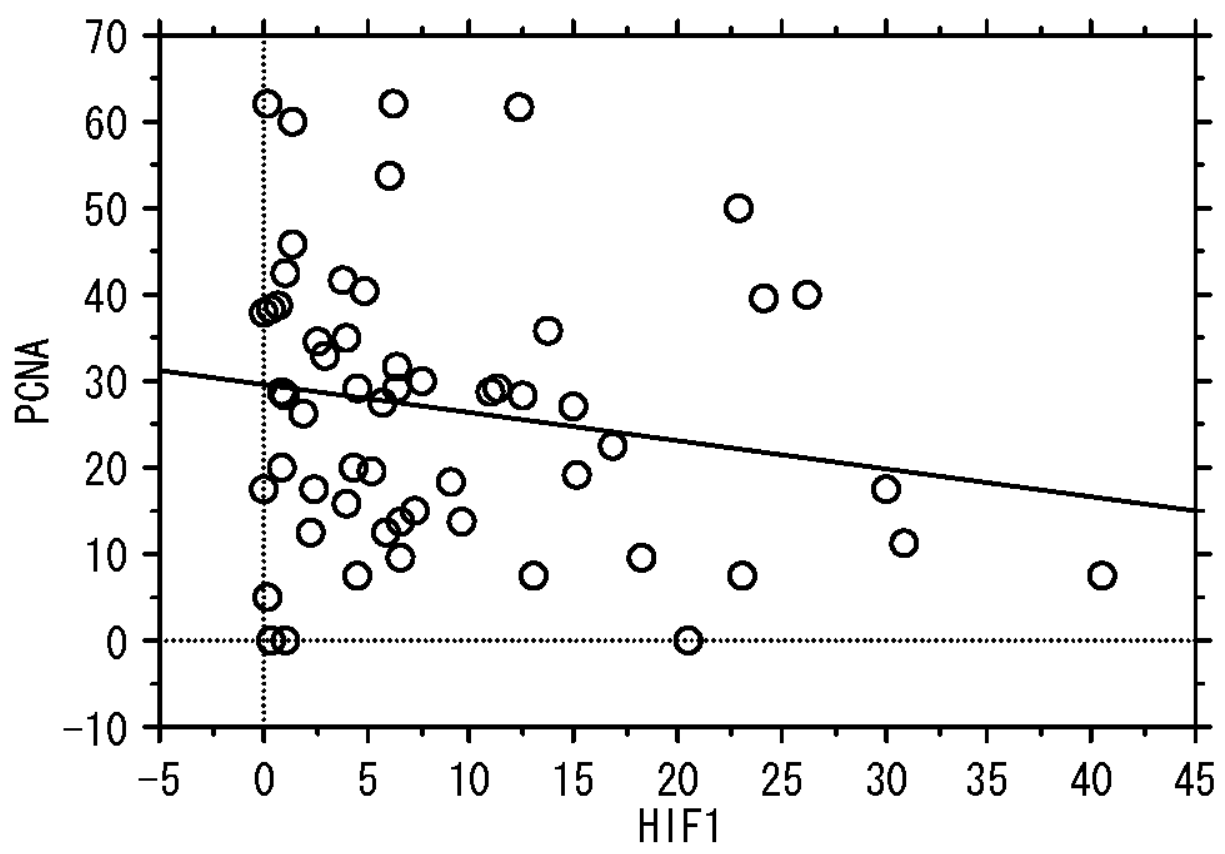

$$
\text { PCNA }=29.445-.321 * \mathrm{HIF} 1 ; \mathrm{R}^{\wedge} 2=.033
$$

Figure 4 